\title{
Comparative Analysis of Optical Biometry and Conventional Ultrasound A-Scan for Biometric Calculations of Eye
}

\author{
Bhairavi S Raut ${ }^{1}$, Meena G Menon ${ }^{2}$, Umesh $\mathbf{Y}^{3}$ \\ ${ }^{1}$ Fellow, Glaucoma Department, Sankara Eye Hospital, Bangalore \\ ${ }^{2}$ HOD, Glaucoma Department, Sankara Eye Hospital, Bangalore \\ ${ }^{3}$ Chief Medical Officer, Sankara Eye Hospital, Bangalore
}

\begin{abstract}
Aim: To evaluate the predictability of refractive outcome using optical and ultrasound biometry in getting near emmetropia post operatively and to compare the axial length (AL), intraocular lens (IOL) power measured with Lenstar LS 900 with those obtained with ultrasound a-scan (Echorule2, Biomedix) in cataract patients. Material \& methods: After proper clearance from the ethical committee, the data of 231 eyes of 138 adult patients who had undergone surgery for visually significant cataract in one or both eyes at our centre was analyzed retrospectively for the study. Every eye had undergone two measurements each with an optical biometer (OS) (Lenstar, Haag Striet) and with ultrasound A-scan (UAS) (Echorule2, Biomedix). Optical biometry was performed first followed by ultrasound measurements. SRK-T formula was used for calculation of IOL power. Results: The mean axial length of measured with OS was $23.46 \pm 1.50 \mathrm{~mm}$ (range, 20.62-31.87 mm) and that measured with $U A S$ was $23.37 \pm 1.52 \mathrm{~mm}$ (range, 20.2-32.29mm). The axial lengths were compared using independent $t$-test, the p-value $(0.526)$ was not found to be statistically significant and the mean difference was 0.089. The mean IOL measured with $O S$ was $20.67 \pm 4.35 \mathrm{D}$ and that measured with UAS was $20.86 \pm 4.32 \mathrm{D}$. The IOL powers were compared using independent t-test, the p-value (0.63) was not found to be statistically significant and the mean difference was -0.19 . The Bland-Altman plots showed good agreement between devices with less than $5 \%$ of eyes that were outliers. In both the groups, majority of the patients had spherical equivalents within $\pm 1 D$. On comparison, the post-operative refraction was not statistically significant. Conclusion: Optical biometry with OCLR technology to measure axial length is very precise and interchangeable with ultrasound measurement with no clinical difference in post-operative refraction in cataract patients.
\end{abstract}

Keywords: Biomedix, Lenstar, Axial length, IOL

\section{Introduction}

Phacoemulsification and foldable intraocular lens (IOL) implantation has led to improved success rates and faster visual rehabilitation in patients undergoing cataract surgery. The refractive outcome following phacoemulsification cataract surgery is dependent on a number of factors ${ }^{1-3 .}$ They include axial length measurement, keratometry, anterior chamber depth, IOL power formulae, and the quality of the IOL. Of these factors, inaccurate axial length measurements were shown to be the major deterrent to the predictability of the refractive outcome ${ }^{4-5}$. Since the predictability of refractive outcome is based on the accuracy of preoperative biometry, the methods used in biometry continue to evolve. ${ }^{6-}$ 12

Ultrasound measurements can be performed by contact of an ultrasound probe to the cornea or by immersion of the probe in a saline filled shell. Ideal measurements consist of three readings within $0.02 \mathrm{~mm}$ of each other, maximally high, with steeply rising anterior and posterior lens and retina spikes.

The Lenstar LS 900 is a non-invasive, non-contact OLCR (optical low-coherence reflectometry) biometer used for obtaining ocular measurements and performing calculations to assist in the determination of the appropriate power and type of IOL for implantation following cataract removal. FDA approval was done in 2009. It uses a superluminescent diode as the laser source for the measurement of the axial length of the patient's eye, precisely on the patient's visual axis, in the presence of dense media. One LENSTAR ${ }^{\circledR}$ scan consists of 16 individual full eye scans and 4 individual keratometric scans, taken on 2 concentric rings, along the patient's visual axis. One scan takes 9 different measurements in 30 seconds. All of the standard IOL prediction formulas (Holladay I, SRK-T, Haigis and Hoffer Q) are built into the software with potential for future formulas to be added.

Previous comparisons of ultrasound biometry and optical biometry have reported equal or better results with optical biometry $^{15-18}$. However the difference in measurement principles, measurement of differing ocular structures (e.g. corneal apex to ILM for ultrasound) and other factors indicate need of further investigation. In this study we compared the refractive outcome in cataract surgery following biometry with the applanation A-scan ultrasound and OCLR. The aim of the study was to evaluate the predictability of refractive outcome using optical and ultrasound biometry in getting near emmetropia post operatively and to compare the axial length (AL), intraocular lens (IOL) power measured with Lenstar LS $900(\AA)$ with those obtained with ultrasound a-scan (Echorule2, Biomedix) in cataract patients.

\section{Materials and Methods}

After proper clearance from the ethical committee, the data of 231 eyes of 138 adult patients who had undergone surgery 


\section{International Journal of Science and Research (IJSR) \\ ISSN (Online): 2319-7064 \\ Index Copernicus Value (2015): 78.96 | Impact Factor (2015): 6.391}

for visually significant cataract in one or both eyes at our centre was analysed retrospectively for the study. All of the subjects included in the study had nucleus sclerosis grade 23. All the subjects included were free from contact lens wear for two weeks before the examination and had astigmatism equal to or less than 2.00 D. Patients were excluded if they had dense cataracts, sub capsular cataracts, media opacities, history of trauma, corneal abnormalities, active ocular pathology, and previous ocular surgery, fixation instability caused by macular degeneration or amblyopia. All eyes had undergone a standardised comprehensive ophthalmologic examination comprising uncorrected distance vision (UDV), manifest refraction, slit lamp biomicroscopy and fundus examination.

Every eye had undergone two measurements each with an OCLR biometer (OS) (Lenstar, Haag Striet) and with ultrasound A-scan (UAS) (Echorule2, Biomedix). Three consecutive measurements of axial length were taken in a single session using UAS and the Lenstar and a mean calculated. Optical biometry was performed first followed by ultrasound measurements to avoid the confounding effect of a potential corneal abrasion. SRK-T formula was used for calculation of IOL power. The measurement of axial length with UAS was done only by contact method. Emersion technique for UAS was not utilised. All eyes were measured by a single experienced technician.

All eyes were operated by single surgeon using phacoemulsification technique with similar parameters and foldable PCIOL was implanted in the capsular bag. The IOLs used in the study were one-piece acrylic IOLs. All of the surgeries were suture less. Manifest refraction, uncorrected visual acuity, best corrected visual acuity, was assessed at 1 week after the surgery. The difference between achieved and predicted refraction was noted. The patients were further subdivided into two groups based on IOL power calculated by either of the two instruments was used and the postoperative refraction amongst the two groups was compared using the spherical equivalent.

Comparison, correlation and repeatability of axial length of the eye with optical biometer and ultrasound biometer were analysed. Bland-Altman plots were used to evaluate the agreement in axial length and IOL power between devices with $95 \%$ confidence intervals.

\section{Results}

The study sample was comprised of 138 (231 eyes) patients with a mean age of $59.04 \pm 16.26$ years (range, $40-84$ years). 165 eyes $(71.42 \%)$ belonged to male patients.

The mean axial length of measured with OS was $23.46 \pm$ $1.50 \mathrm{~mm}$ (range, $20.62-31.87 \mathrm{~mm}$ ) and that measured with UAS was $23.37 \pm 1.52 \mathrm{~mm}$ (range, $20-32.29 \mathrm{~mm}$ ). The axial lengths were compared using independent t-test, the $\mathrm{p}$-value (0.526) was not found to be statistically significant and the mean difference was 0.089. (Table-1, 2)
The mean IOL measured with OS was $20.67 \pm 4.35$ Dioptres (D) and that measured with UAS was $20.86 \pm 4.32 \mathrm{D}$. The IOL powers were compared using independent $t$-test, the $p$ value (0.63) was not found to be statistically significant and the mean difference was -0.19 . (Table-1, 3)

Table 1: Mean AXL and IOL power calculated by both

\begin{tabular}{|c|c|c|c|c|}
\hline$(\mathrm{n}=234)$ & Lenstaar & Biomedix & Mean Difference & P-Value \\
\hline Axial Length & $23.46 \pm 1.50$ & $23.37 \pm 1.52$ & 0.089 & 0.526 \\
\hline IOL power & $20.67 \pm 4.35$ & $20.86 \pm 4.32$ & -0.19 & 0.637 \\
\hline
\end{tabular}

Table 2: Mean axial length in Group A, B \& C calculated by both instruments compared by t-test

\begin{tabular}{|c|c|c|c|c|}
\hline Axial Length & Lenstaar & Biomedix & MD & P-Value \\
\hline Group & Mean \pm SD & Mean \pm SD & & \\
\hline $\mathrm{A}(\mathrm{n}=174)$ & $23.01 \pm 0.55$ & $22.95 \pm 0.54$ & 0.097 & 0.096 \\
\hline $\mathrm{B}(\mathrm{n}=16)$ & $21.54 \pm 0.39$ & $21.53 \pm 0.32$ & 0.001 & 0.992 \\
\hline $\mathrm{C}(\mathrm{n}=43)$ & $25.91 \pm 1.82$ & $25.83 \pm 1.92$ & 0.087 & 0.833 \\
\hline
\end{tabular}

Table 3: Mean IOL power in Group A, B \& C calculated by both instruments compared by t-test

\begin{tabular}{|c|c|c|c|c|}
\hline IOL power & Lenstaar & Biomedix & MD & P-Value \\
\hline Group & Mean \pm SD & Mean \pm SD & & \\
\hline $\mathrm{A}(\mathrm{n}=174)$ & $14.15 \pm 6.18$ & $14.41 \pm 6.27$ & -0.27 & 0.846 \\
\hline $\mathrm{B}(\mathrm{n}=16)$ & $21.86 \pm 1.72$ & $22.07 \pm 1.72$ & -0.21 & 0.256 \\
\hline $\mathrm{C}(\mathrm{n}=43)$ & $24.60 \pm 2.47$ & $24.37 \pm 2.22$ & 0.23 & 0.788 \\
\hline
\end{tabular}

To further evaluate the sample data, we subdivided the patients into three groups based on the axial lengths- Group A $(22-24 \mathrm{~mm})$, Group B $(<22 \mathrm{~mm})$ And Group C (>24$32 \mathrm{~mm})$. In Group A there were 174 eyes with axial lengths ranging between 22 to $24 \mathrm{~mm}$. In Group B, there were 16 eyes with axial lengths $<22 \mathrm{~mm}$. In Group C, there were 41 eyes, with $\mathrm{AL}>24 \mathrm{~mm}$. In all three groups, the mean axial length and IOL power measured with OS and UAS were compared using independent t-test, the p-value was not found to be statistically significant. (Table-2, 3)

Bland-Altman analysis was used to assess inter observer repeatability of UAS and the OS as well as agreement between the OS and UAS for axial length measurement and intraocular lens power calculation. In both, Bland-Altman plots (Figs. 1 \& 2), the 95\% limits of agreement (mean difference $\pm 1.96 \mathrm{SD}$ ), which define the range that encompassed most differences between the measurements with the two methods, were calculated to plot the graphs. Figure-1 shows a graph of the differences between the readings of axial length using the UAS and the Lenstar. Figure-2 show graphs of the differences between the readings of IOL power using the UAS and the Lenstar. 


\section{International Journal of Science and Research (IJSR) \\ ISSN (Online): 2319-7064}

Index Copernicus Value (2015): 78.96 | Impact Factor (2015): 6.391

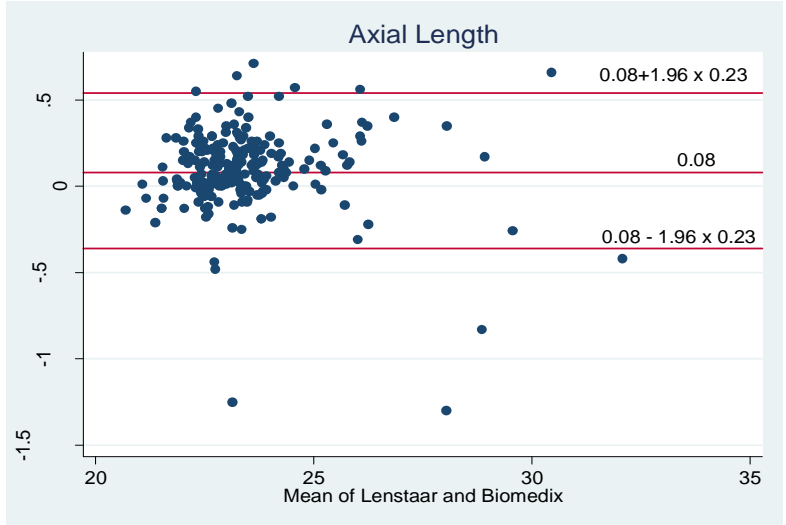

Figure 1: Blant-Altman analysis plot for comparision of axial length calculated by Lenstaar \& biomedix

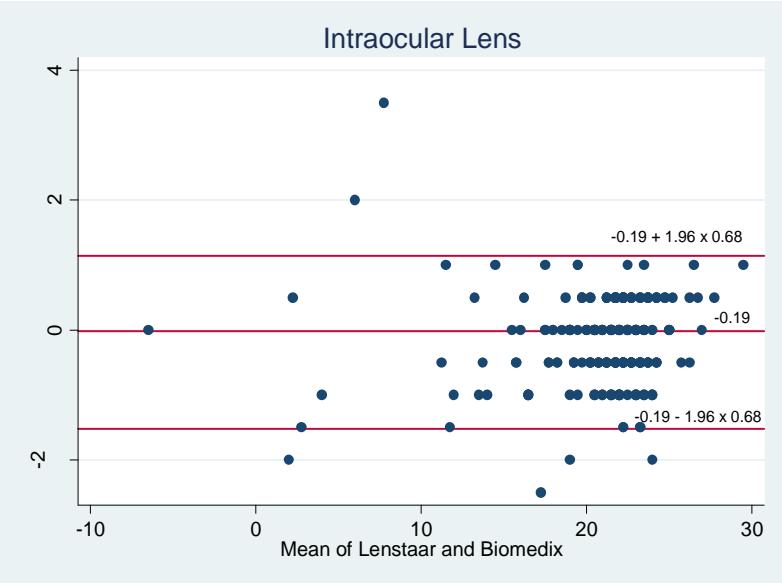

Figure 2: Blant-Altman analysis plot for comparision of IOL power calculated by Lenstaar \& biomedix

The biometric parameters of axial length \& IOL power obtained by the Lenstar and the contact devices significantly correlated with each other. Thus, there was agreement between the instruments for the AL and IOL power values.

To compare the post-operative refraction, the patients were further subdivided into two groups- Lenstar group (in whom IOL power as calculated by OS was used) and Biomedix group (in whom IOL power as calculated by UAS was used). The spherical equivalent was taken into consideration for analysis. Out of the 231 eyes that were analysed, 194 eyes underwent cataract surgery. Patients lost to follow up were not taken for analysis.

In Lenstar group, there were 94 patients and in biomedix group 100 patients. In both the groups, majority of the patients had spherical equivalents within $\pm 1 \mathrm{D}$. On comparison with unpaired t-test, the post-operative refraction was not statistically significant. (Table-4)

Table 4: Comparision of post-operative refraction amongst two groups

\begin{tabular}{|c|c|c|c|c|}
\hline $\begin{array}{c}\text { Post op } \\
\text { refraction }\end{array}$ & $\begin{array}{c}\text { Lenstaar } \\
(\mathrm{n}=94)\end{array}$ & $\begin{array}{c}\text { Biomedix } \\
(\mathrm{n}=100)\end{array}$ & $\begin{array}{c}\text { Mean } \\
\text { Difference }\end{array}$ & $\begin{array}{c}\text { P- } \\
\text { Value }\end{array}$ \\
\hline Group & Mean \pm SD & Mean \pm SD & & \\
\hline $\mathrm{A}(22-24 \mathrm{~mm})$ & $0.09 \pm 0.45$ & $0.03 \pm 0.55$ & 0.66 & 0.49 \\
\hline $\mathrm{B}(<21 \mathrm{~mm})$ & $0.28 \pm 0.33$ & $-0.125 \pm 0.72$ & 0.41 & 0.103 \\
\hline $\mathrm{C}(>24 \mathrm{~mm})$ & $0.15 \pm 0.53$ & $0.11 \pm 0.61$ & 0.03 & 0.838 \\
\hline Total $(\mathrm{n}=194)$ & $0.135 \pm 0.46$ & $0.0425 \pm 0.57$ & 0.09 & 0.214 \\
\hline
\end{tabular}

\section{Discussion}

Precise biometry is essential for accurate outcomes in cataract and refractive surgeries. Ultrasound axial length measurements have been the gold standard for many years. With the introduction of optical biometry, technology has become more advanced.

The differences between ultrasound biometry and optical biometry have clinical implications. Firstly, resolution improves as wavelength decreases. Hence, as light has a very short wavelength compared to sound, the laser light has better resolution. Therefore, the accuracy of ultrasound AL is approximately $0.10-0.12 \mathrm{~mm}$ compared to $0.01 \mathrm{~mm}$ for optical AL. Measurement accuracy is limited by variation in retinal thickness surrounding the fovea. The second difference is the starting point of measurement between the two modalities. The ultrasound measures $\mathrm{AL}$ from the anterior surface of the corneal apex to the internal limiting membrane (ILM) of the fovea, whereas optical biometry measures AL from the second principal plane of the cornea (0.05 $\mathrm{mm}$ deeper than the corneal apex) to photoreceptor layer $(0.25 \mathrm{~mm}$ deeper than ILM) of the fovea. Theoretically, optical biometry reads longer than ultrasonic axial length ${ }^{13,14}$

Lastly, ultrasound measurements are performed on the anatomic axis i.e. through the centre of the cornea measuring anatomic axis as axial length whereas optical biometry measurements are performed on the visual axis measuring visual axis as axial length. As visual axis is shorter than anatomic axis; hence, optical measurements read shorter axial length compared to ultrasound measurements ${ }^{13}$.This translates into a $0.3-0.5 \mathrm{~mm}$ difference in the axial length or 1-1.5 D of IOL power. Hence the OS gives lower IOL power compared to the UAS. The additional difference can occur taking into account the indentation of cornea while measuring with UAS.

In our study, on comparison of axial length and IOL power calculated by both machines the mean difference was found to be 0.089 and 0.19 . The Bland-Altman plots showed good agreement between devices with less than $5 \%$ of eyes that were outliers (Fig. $1 \& 2$ ). Thus, practically the difference is not clinically significant. There was no significant difference in the predicted post-operative refractive outcome between UAS biometry and Lenstar LS 900(®). Based on the results, the conventional ultrasound A-scan technique is as accurate as Lenstar LS 900(®) in the hands of an experienced operator. We found that the calculation of IOL power based on ocular axial length measurement with OCLR technology provided no clinical advantage over conventional ultrasound A-scan.

The limitations of this study are small sample size and retrospective analysis. The outcomes of the current study are similar to previous publications ${ }^{15-17,19 .}$ One study had shown greater measurement of AL with Lenstar LS 900 but was done on paediatric population ${ }^{18}$. 


\section{International Journal of Science and Research (IJSR) \\ ISSN (Online): 2319-7064}

Index Copernicus Value (2015): 78.96 | Impact Factor (2015): 6.391

\section{Conclusions}

Based on the outcomes of this study we advise that optical biometry with OCLR technology to measure axial length is very precise and interchangeable with ultrasound measurement with no clinical difference in post-operative refraction in cataract patients..

Thus Lenstar LS 900 provides quick and accurate assessment of biometric parameters in busy clinical practices and high volume centres. It is a device that provides sophisticated technology in a user-friendly package without risk of any corneal abrasion. Today, we see a lot of patients who had LASIK 10 or 15 years ago and are now reaching cataract age. That used to be a once-in-a-while thing; now it's a daily routine. In these demanding cases, having a unit that can accurately and reproducibly provide the IOL power is essential.

There is still a role for ultrasound biometry to measure axial length in the presence of a very dense cataract, subcapsular cataracts, media opacities, corneal edema where optical biometry is not useful. Ultrasound does not require the patient to fixate on a target. As well, ultrasound A-scan is fine for the majority of patients with normal eye anatomy. Perhaps the biggest advantage of ultrasound biometry units is the cost. It is much more affordable than optical biometry, but requires more operator skill to ensure consistent accuracy. This study shows that even with conventional instruments good quality of vision can be given to patients undergoing cataract surgery at costs which are affordable to the patient and the surgeon.

\section{References}

[1] Olsen T. Sources of error in intraocular lens power calculation. J Cataract Refract Surg 1992; 18: 125-129

[2] Hoffer KJ. The Hoffer Q formula: a comparison of theoretic and regression formulas. $J$ Cataract Refract Surg 1993; 19: 700-712

[3] Binkhorst RD. The accuracy of ultrasonic measurement of the axial length of the eye. Ophthalmic Surg 1981; 12: 363-365

[4] Holladay JT, Prager TC et al. Improving the predictability of intraocular lens power calculations. Arch Ophthalmol 1986; 104: 539-541

[5] Olsen T. Theoretical approach to intraocular lens calculation using Gaussian optics. J Cataract Refract Surg 1987; 13: 141-145

[6] Oslen T. The accuracy of ultrasonic determination of axial length in pseudophakic eyes. Acta Ophthalmol (Copenh) 1990; 67: 141-144

[7] Bamber JC, Tristam M. Diagnostic ultrasound. In: Webb S (ed). The Physics of Medical Imaging Philadelphia: Adam Hilger 1988 319-388

[8] Fercher AF, Mengedoht K, Werner W. Eye length measurement by interferometry with partial coherent light. Opt Lett 1988; 13: 186-188

[9] Huang D, Swanson EA, Lin CP et al. Optical coherence tomography. Science 1991; 254: 1178-1181
[10] Hitzenberger CK. Optical measurement of the axial length by laser Doppler interferometer. Invest Ophthalmol Vis Sci 1991; 32: 616-624

[11] Hitzenberger CK et al. Measurement of the axial length of cataract eyes by laser Doppler interferometry. Invest Ophthalmol Vis Sci 1993; 34: 1886-1893

[12] Drexler W, Findl O et al. Dual beam optical coherence tomography: signal identification for ophthalmologic diagnosis. J Biomed Opt 1998; 3: 55-65

[13] Holladay JT. Ultrasound and optical biometry. Cataract Refract Surg Today Eur 2009.

[14] Alpins NA, Walsh G. accurate biometry and intraocular lens power calculations. In: Agarwal A, editor. Refractive Surgery Nightmares - Conquering Refractive Surgery Catastrophes. NJ: Slack Inc; 2008. p. 581585.8 .

[15] Naicker P, Sundralingam S, Peyman M et al. Refractive outcomes comparison between the Lenstar LS 900® optical biometry and immersion A-scan ultrasound. Int Ophthalmol. 2015 Aug;35(4):459-66

[16] Christoph Tappeiner, Kaspar Rohrer, Beatrice E Frueh, Rudolf Waelti, David Goldblum. Clinical comparison of biometry using the non-contact optical low coherence reflectometer (Lenstar LS 900) and contact ultrasound biometer (Tomey AL-3000) in cataract eyes-Br $J$ Ophthalmol 2010; 94: 666-667

[17]P J Buckhurst, J S Wolffsohn, S Shah, S A Naroo, L N Davies et al. A new optical low coherence reflectometry device for ocular biometry in cataract patients. British Journal of Ophthalmology. Volume 93(7), July 2009

[18] Gursoy H, Sahin A, Basmak H, Ozer A, Yildirim N et al. Lenstar versus ultrasound for ocular biometry in a pediatric population. Optom Vis Sci.2011 Aug;88(8):912-9

[19]Pipat Kongsap. Comparison of a new optical biometer and a standard biometer in cataract patients. Eye and Vision; 2016 Oct 17.

\section{Author Profile}

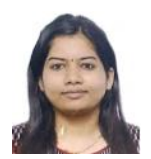

Dr. Bhairavi Suresh Raut received the MBBS degree from MUHS, NASHIK in 2010. Then she received M.S (Ophthalmology) degree from S.N. Medical College Agra in 2015. From 2015-2017 she has been working at Sankara Eye Hospital Bangalore as glaucoma fellow. 